\title{
Gone with the wind: Is signal timing in a neotropical katydid an adaptive response to variation in wind-induced vibratory noise?
}

\author{
Estefania Velilla $^{1,2}$ (D) $\cdot$ Matías Muñoz ${ }^{1} \cdot$ Nicol Quiroga $^{3} \cdot$ Laurel Symes $^{4,2} \cdot$ Hannah M. ter Hofstede $^{5,2} \cdot$ Rachel A. Page $^{2} \cdot$ \\ Ralph Simon ${ }^{1} \cdot$ Jacintha Ellers ${ }^{1} \cdot$ Wouter Halfwerk $^{1}$
}

Received: 27 January 2020 / Revised: 3 April 2020 / Accepted: 20 April 2020 / Published online: 4 May 2020

(C) The Author(s) 2020

\begin{abstract}
Wind, a major source of environmental noise, forces invertebrates that communicate with plant-borne vibrations to adjust their signaling when communicating in windy conditions. However, the strategies that animals use to reduce the impact of wind noise on communication are not well studied. We investigated the effects of wind on the production of tremulatory signals in the neotropical katydid Copiphora brevirostris. First, we recorded katydid signaling activity and natural wind variation in the field. Additionally, we exposed katydid couples during their most active signaling time period to artificial wind of different levels, and we recorded the number of tremulations produced by the males. We found that wind levels are at their lowest between 2:00 and 5:00 in the morning, which coincides with peak signaling period for male katydids. Furthermore, we found that males produce significantly fewer tremulations when exposed to wind rather than acoustic noise or silence. Wind velocity significantly affected the number of tremulations produced during the wind treatment, with fewer tremulations produced with higher wind velocities. Our results show that katydids can time their vibratory signaling both in the short- and long-term to favorable sensory conditions, either through behavioral flexibility in response to short-term fluctuations in wind or as a result of an evolutionary process in response to predictable periods of low-wind conditions.
\end{abstract}

\section{Significance statement}

Animal communication can be hampered by noise across all sensory modalities. Most research on the effects of noise and the strategies to cope with it has focused on animals that use airborne sounds to communicate. However, although hundreds of thousands of invertebrates communicate with vibrational signals, we know very little about how noise affects this form of communication. For animals that rely on substrate-borne vibrations, wind represents the major source of environmental noise. Wind velocity levels can be predictable at a long-term scale (hours) but rather unpredictable at a short time scale (seconds). Both scales of variation are important for communication. Using a combination of field observations and lab experiments, we investigated the strategies used by a neotropical katydid Copiphora brevirostris to cope with vibrational noise induced by wind. Our results demonstrate that $C$. brevirostris times its signals at the long- and short-term range. Katydids signaled more at the times at night when wind velocity was lowest. Moreover, when exposed to wind gusts during their peak time of activity, katydids signaled more during the wind-free gaps.

Keywords Communication $\cdot$ Katydids $\cdot$ Neotropics $\cdot$ Signal timing $\cdot$ Tremulations $\cdot$ Wind

Communicated by J. C Choe

Estefania Velilla

e.velillaperdomo@vu.nl

1 Department of Ecological Science, Vrije Universiteit Amsterdam, De Boelelaan 1085, 1081 HV Amsterdam, The Netherlands

2 Smithsonian Tropical Research Institute, Apartado, 0843-03092 Panamá, República de Panamá
3 Departamento de Ciencias Ecológicas, Facultad de Ciencias, Universidad de Chile, Santiago, Chile

4 Center for Conservation Bioacoustics, Cornell Lab of Ornithology, 159 Sapsucker Woods Road, Ithaca, NY, USA

5 Department of Biological Sciences, Dartmouth College, 78 College Street, Hanover, NH, USA 


\section{Introduction}

Animals make decisions about when and where to search for mates, to look for food, or to hide from predators based on signals and cues available in their environment (Halfwerk et al. 2016a, 2016b). Wind- and rain-induced vibrations impose different selection pressures on multimodal signaling (Bradbury and Vehrencamp 1998). The decisions made based on these signals and cues have crucial consequences for an animal's survival and reproductive success (Bradbury and Vehrencamp 1998), emphasizing the importance of reliability of environmental information (Dall et al. 2005). Noise in the environment, however, can affect the reliability with which information in the environment travels from sender to receiver, altering the behavior of senders and hampering detection by receivers (Brumm and Slabbekoorn 2005; Naguib 2013; Velilla and Halfwerk 2019). Consequently, animals have evolved to cope with noise by adapting their behavior and/or their signal production mechanisms (Brumm and Slabbekoorn 2005; Brumm 2006).

Research on the effects of noise on signaling has mostly focused on animals that communicate with airborne sound. However, noise can be referred to as any stimulus that reduces signal perception in any sensory modality (Brumm and Slabbekoorn 2005; Brumm 2013; Velilla and Halfwerk 2019). For example, electric noise from lighting storms affect predator-prey dynamics among electric fish (Hopkins 1973), and light noise from artificial lighting reduces flashing activity in fireflies (Firebaugh and Haynes 2016). Moreover, chemical noise from anthropogenic pollutants affects social recognition and shoaling in fish (Ward et al. 2008). The effect of noise on vibratory communication is, however, greatly understudied.

Vibrational signals and cues are used by hundreds of thousands of invertebrates, and many vertebrates as well, and vibration is the second-most widely documented communication modality after the chemical modality (Cocroft et al. 2014). Animals communicating with plant-borne vibrations are particularly likely to be affected by noise caused by wind (reviewed in Virant-Doberlet et al. 2014). As wind shakes the leaves and branches of plants, it induces vibrational noise, mostly at low frequencies (Barth et al. 1988; Casas et al. 1998; Cocroft and Rodriguez 2005). Wind velocity can be predictable for a given location in the course of a day and night, whereas short-term fluctuations in wind velocity can be highly unpredictable (Tishechkin 2007). Both scales of environmental variation can be important for communication, as has already been shown in the airborne acoustic domain for the swamp sparrow and the white-throated sparrow (Brown and Handford 2003), a neotropical treefrog (Schwartz and Wells 1983), and the Eastern willet (Douglas and Conner 1999). Animals could adapt to communicating in windy conditions by increasing the amplitude of their signals or by altering their signals to avoid spectral overlap. A different and less energy-costly strategy, however, would be to time signal to low-wind time periods and to wind-free gaps, as has been shown for treehoppers and small homopterans (McNett et al. 2010; Tishechkin 2013; Halfwerk et al. 2016b).

Many neotropical katydid species communicate with both acoustic and vibrational signals. Most research on katydid communication has focused on their acoustic signals, although the vibrational signals and signaling behavior of some katydid species have been recorded and described (Morris et al. 1994; Römer et al. 2010; De Souza et al. 2011; Sarria$S$ et al. 2016). Katydid vibrational signals, also called tremulations, are mate advertisement signals and are generated by rhythmic shaking of the abdomen, resulting in vibrations that propagate through the plant substrate. These signals contain most of the energy at low frequencies $<100 \mathrm{~Hz}$ (Morris et al. 1994) and could therefore be masked by wind noise. Copiphora brevirostris, a common species found mostly in the rainforest understory, produces both acoustic and vibrational signals and relies heavily on vibrational signaling (Morris et al. 1994). Copiphora brevirostris tremulates in the context of courtship and male-male interactions and does not need a female to be on the same substrate or even in the vicinity in order to signal (pers. obs). A similar behavior has been recorded for the congenic species Copiphora rhinoceros by Morris (1980), where males tremulate both reciprocally and in the absence of replies and also do so in the presence and in the absence of females and/or conspecific males. The acoustic signals are short and mainly ultrasonic (30 ms duration and $32 \mathrm{kHz}$ peak frequency; ter Hofstede et al., in press). The acoustic signals are only produced sporadically throughout the night (44.4 calls per $24 \mathrm{~h}$; Symes et al. in review) and alternate with intervals of tremulations (Morris et al. 1994; Hamel et al. in preparation).

In this study, we test the hypothesis that $C$. brevirostris adaptively adjusts its signaling behavior to reduce the impact of wind noise on signal transmission. We measured natural wind velocity variation in the field, observed signaling activity, and conducted a wind exposure experiment to test the effect of wind over long- and short-term time scales. In our signaling activity observations, we paired male and female katydids to induce tremulatory behavior, and we studied the relationship between peak time in signaling activity and variation in wind levels. In our wind exposure experiment, we exposed katydid couples to 3-min wind gusts of different velocities, as well as two control conditions, and counted the number of male tremulations during each condition. One control condition had no wind, (here forth called "silent"), and one control condition was exposure to the sounds generated by the experimental wind setup (referred to as the "sound" treatment). We predicted that $C$. brevirostris would (1) signal at times of day when wind is typically low and (2) adjust their signaling activity in response to short-term fluctuations in wind. 


\section{Materials and methods}

\section{Study area and animals}

We conducted experiments at the Smithsonian Tropical Research Institute's field stations in Gamboa, Panama, from April to July 2018 and on Barro Colorado Island (BCI) from March to May 2019. Copiphora brevirostris were collected from the vegetation along pipeline road in Gamboa and on the forest trails of BCI. Animals were separated by sex, housed in net cages, and fed with apple, dry cat food, and water. Collection of animals and experiments were approved by the Ministry of Environment of Panama, scientific permit No. SE/ A-22-18.

\section{Characterizing C. brevirostris tremulatory signal}

We recorded the tremulation of a single male $C$. brevirostris using a Laser Doppler Vibrometer (LDV) (Polytec PDV-100, sampling rate $44.1 \mathrm{kHz}$ ). The output of the laser was recorded as a .wav file using an audio recorder (Tascam 60D MKII, $44.1 \mathrm{kHz}, 16$-bit resolution). We placed a male katydid together with a female in a custom-made nylon mesh cage $\left(20 \mathrm{~cm}^{3}\right)$, and we put a $1 \mathrm{~cm}^{2}$ reflective tape on one side of the cage. We recorded male tremulations when the male's legs were positioned on the mesh containing the reflective tape, and the female was not on the same panel of the cage.

\section{Measuring natural wind variation}

We recorded wind data for five consecutive nights from 22:00 at night to 08:00 in the morning, for three different trails on BCI (Donato, Geostation, and Snyder Molino) between March and May 2019 on the forest trails of BCI. These were the same forest trails where katydids were collected in the same year. A wind meter (Kestrel 5500) was attached to a small tree at approximately $1.5 \mathrm{~m}$ height. Peak wind velocity was logged every minute, with a 2-s integration time. To explore general wind patterns throughout the night, we plotted the mean peak wind velocity per minute across all nights and trails $(n=15)$. Additionally, we used the max peak wind velocity (highest wind velocity recorded per minute across all nights and trails) to guide our selection of wind gust levels. Using a LDV, we measured wind-induced vibrations from natural wind on an Oenocarpus $s p$. palm and wind-induced vibrations from artificial wind on the cage on which the animals were tested. In both cases, we also recorded wind velocity with a wind meter.

\section{Measuring signaling activity}

Signaling activity was measured during July 2018 in Gamboa, Panama. Using a camcorder with night vision (Sony DCR-
SR45), we recorded the behavior of five katydid couples from 22:00 at night to 06:00 in the morning. We decided to start at 22:00 based on pilot recordings where we found no activity in the earlier hours of the evening. Katydids were placed in a custom-made nylon mesh cage $\left(20 \mathrm{~cm}^{3}\right)$ with food and water. There were no plants inside the cage. The animals were placed in the cage $2-3 \mathrm{~h}$ before starting observations to let them acclimatize. Observations took place in a closed lab with an ambient temperature of $29^{\circ} \mathrm{C}\left(\mathrm{SD} \pm 3{ }^{\circ} \mathrm{C}\right)$, where they were protected from wind and rain. There were no observers present in the room during the recordings. Katydids were taken out of the experimental cage the following morning and placed in a separate cage, separate from the animals that had not been tested yet. Individual animals were used only once per experiment. We released the katydids after all experiments were finished to avoid re-catching the same animals. The videos were analyzed in VLC media player version 3.0.7.1. Male tremulations were quantified from the videos by counting the total number of tremulations produced every hour.

\section{Wind exposure experiment}

The wind exposure experiment was carried out between March and May 2019 in a closed lab on BCI with an ambient temperature of $29^{\circ} \mathrm{C}\left(\mathrm{SD} \pm 3{ }^{\circ} \mathrm{C}\right)$, protected from natural wind and rain. We exposed 16 katydid couples to artificially created wind using a computer fan (ebm-papst S-Force Series Axial, $200 \times 50.88 \mathrm{~mm}, 1220 \mathrm{~m}^{3} / \mathrm{h}, 103 \mathrm{~W}, 48 \mathrm{~V} \mathrm{dc}$ ) mounted on a metal base. The fan was positioned in front of the cage $(\sim 1 \mathrm{~m}$ away) but on a separate table to reduce the transmission of vibrational noise from the mechanical engine of the fan. We directed the wind toward (and as a control also away) the cage using a PVC ventilation tube with a diameter of $203 \mathrm{~mm}$. This was done manually by the experimenter who was present in the room at the time of the experiments. Treatment levels were also adjusted by hand by the experimenter.

Katydid couples were placed in the same experimental cage as in the signaling activity experiment, provided with food and water. The pairs were chosen randomly from the communal cages. All individuals were used only once. Behavior was recorded with a camcorder (Sony FDRAX33) coupled with a Led and IR light (Sony HVLLEIR1, 1500 lux). There were no plants inside the cage during the wind exposure experiment. Therefore, katydids signaled from the sides of the cage. We chose to make our behavioral recordings between 02:00 and 04:00 h, because based on our signaling activity data, this was the peak period of signaling activity.

In addition to different wind velocities (here after referred to as "wind" treatment), we also exposed katydid couples to two different control treatments. To control for any effect of the acoustic noise of the fan on katydid signaling, we exposed the katydid couples to the sound 
of the fan only (here after referred to as "sound" treatment). We did this by moving the ventilation tube to the side, so that katydids would be exposed to the sound of the fan, but not the artificial wind. Wind velocity levels at the cage during the sound treatment and the silent control were below $0.1 \mathrm{~m} / \mathrm{s}$, which was the detection threshold of the wind meter. Acoustic noise levels at the cage during the wind and the sound treatment varied from 60 to $70 \mathrm{~dB}$ SPL (A) measured with a Volcroft SPL meter (set to fast and max) (for individual measurements, see Table 1). Furthermore, using a LDV, we measured the vibrations induced by wind on the cage. The sound treatment added very little, if any vibrational noise to the cage in comparison with measurements was done when the fan was turned off. At the treatment level of $0.3 \mathrm{~m} / \mathrm{s}$, vibrational noise for the wind and the sound treatments was low, differing only by $\pm 1 \mathrm{~dB}$ from the silent treatment. At $0.6 \mathrm{~m} / \mathrm{s}$, vibrational noise remained relatively low, with wind vibrational noise levels increased by $4 \mathrm{~dB}$, and acoustic noise showing little increase. The wind treatment at $0.9 \mathrm{~m} / \mathrm{s}$ had vibrational noise $15 \mathrm{~dB}$ higher than the silent treatment, while acoustic noise remained similar to the silent treatment. At $1.5 \mathrm{~m} / \mathrm{s}$, wind produced vibrations that were almost $30 \mathrm{~dB}$ higher in amplitude than the silent levels, while acoustic noise remained similar to the silent treatment (Fig. 1, Table 1). We also included a treatment with no wind or sound (here after referred to as "silent"), which consisted of turning off the fan. Each couple was exposed to wind and sound treatments for four different wind velocities, plus the silent control. Each katydid couple was exposed to four 9-min blocks made up of $3 \mathrm{~min}$ of wind exposure (of a certain velocity), $3 \mathrm{~min}$ of sound treatment exposure, and $3 \mathrm{~min}$ of silent treatment for a total experimental time of $36 \mathrm{~min}$. The treatment and the treatment level (wind velocity) were balanced and randomized per trial. The wind velocities that katydids were exposed to were $0.3,0.6,0.9$, and $1.5 \mathrm{~m} / \mathrm{s}$ and were based on the natural wind variation we found in the field. Only $1.5 \mathrm{~m} / \mathrm{s}$ was slightly higher than our maximum recorded wind velocity.

\section{Signal and statistical analyses}

Signal analyses and statistical analyses were done with $\mathrm{R}$ version 3.3.1 (R Core Team 2016), run in the RStudio interface (RStudio Team 2015).

We calculated the power spectral density using a Hanning window of 2048 samples to measure the spectral characteristics of the tremulatory signal of $C$. brevirostris and compared its distribution to the power spectra for natural wind-induced vibrations and our experimental stimuli (artificial wind, the sound of the fan, and silence).

We used a Friedman test to determine the effect of time at night on the production of male tremulations. Our response variable was the number of tremulations produced by males per hour. Our grouping (predictor) variable was time at night, which we treated as a categorical variable making 1-hr bins starting at 22:00 at night until 6:00 in the morning. We included male as our block variable. To test the effect of treatment and treatment level on the number of male tremulations, we fitted a generalized linear mixed effect model from the $\mathrm{R}$ package "Lme4" (Bates et al. 2015) with Poisson distribution, including male as a random effect. To test whether the fit of the statistical model was improved by the inclusion of treatment and treatment level, we obtained Wald Chi-square statistics from the "Anova" function in the statistical package "Car" (Fox et al. 2011). We ran pairwise comparisons with Bonferroni correction between the treatments at different treatment levels with the R package "Emmeans" (Lenth and Lenth 2018).

\section{Results}

\section{Correspondence between signaling and wind velocity}

We assessed spectral and temporal overlap in signaling and noise. C. brevirostris produced an average of 457 $(\mathrm{SD} \pm 206)$ bouts of tremulations between 22:00 at night and 6:00 in the morning. The tremulation bouts lasted approximately $4-5 \mathrm{~s}$ and consisted of two tremulations

Table 1 Acoustic and vibrational noise levels produced by the fan and the wind from the fan during the different treatments and treatment levels

\begin{tabular}{|c|c|c|c|c|c|c|}
\hline \multirow[b]{2}{*}{ Velocity $(\mathrm{m} / \mathrm{s})$} & \multicolumn{3}{|c|}{ Acoustic noise SPL(A) (dB) } & \multicolumn{3}{|c|}{ Vibrational noise RMS amplitude (dB) } \\
\hline & Silent & Wind & Sound & Silent & Wind & Sound \\
\hline 0.3 & 60 & 60.7 & 60.9 & 24 & 25 & 23 \\
\hline 0.6 & - & 61.8 & 61.2 & - & 28 & 21 \\
\hline 0.9 & - & 65.1 & 62.8 & - & 39 & 22 \\
\hline 1.5 & - & 70 & 66.2 & - & 52 & 20 \\
\hline
\end{tabular}

These measurements were intended to calculate the contribution of each treatment and treatment level to acoustic and vibrational noise levels. Vibrational noise levels for the sound treatment are similar for all treatment levels, indicating that the vibrations from the wind treatment are induced by wind and not by the vibrations from the mechanical motor of the fan or by sound airborne waves that come into contact with the experimental cage 


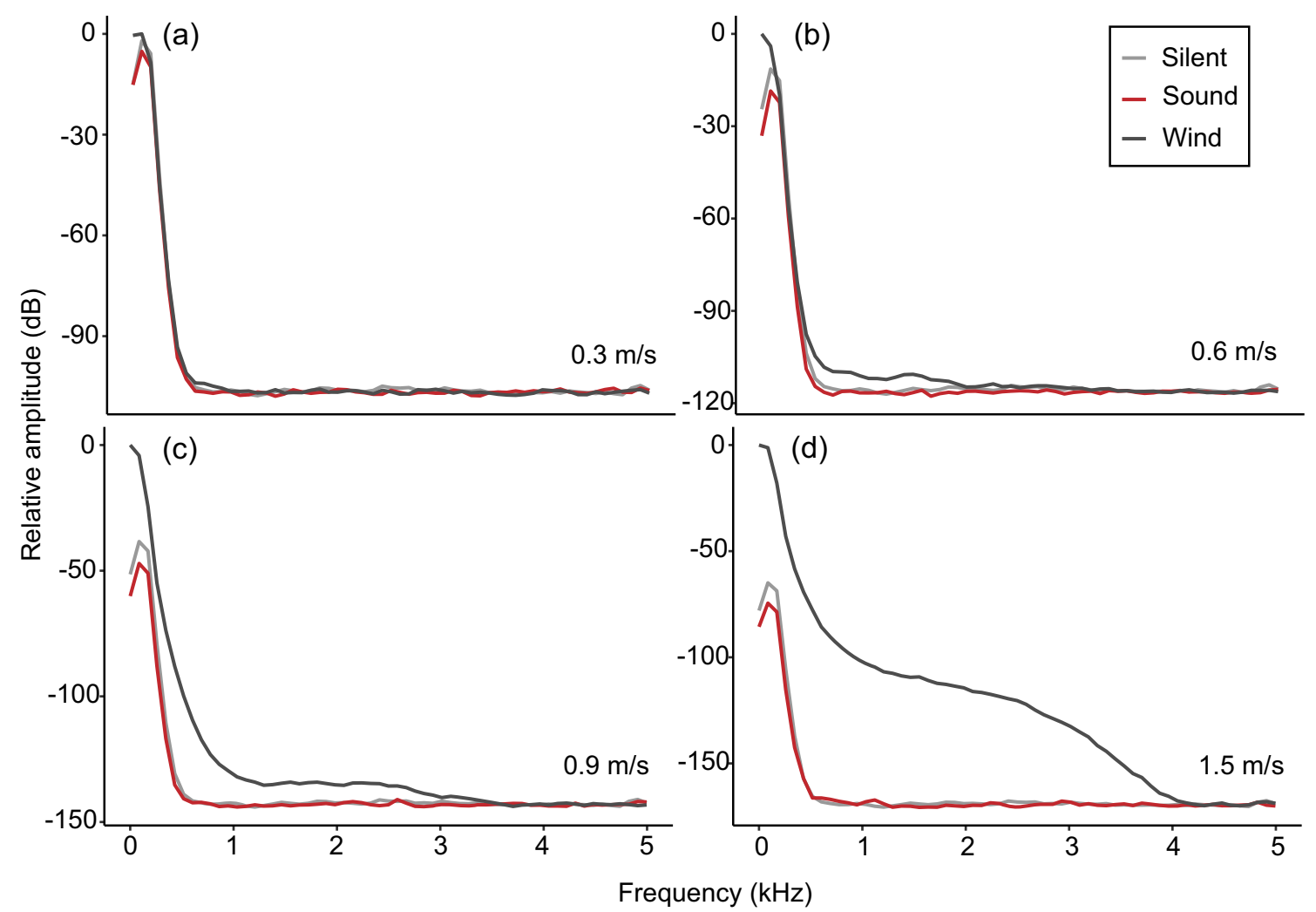

Fig. 1 Spectra of vibrational noise of the artificial wind treatment (fan on and directed toward the cage) and of the sound treatment (ventilation tube set aside) for all the wind velocity treatment levels. Wind velocity levels

per second. Most of the energy in tremulations was concentrated at low frequencies between 80 and $100 \mathrm{~Hz}$ (Fig. 2, but see Morris et al. 1994). Copiphora brevirostris tremulations recorded by Morris et al. (1994) show a slightly lower peak frequency than our recordings. These minor differences are probably due to differences in the substrate used during the recordings. While Morris et al. (1994) recorded with accelerometers on Heliconia plants, we recorded with a LDV on the mesh side of the experimental cage. It is likely that the two substrates have different resonance properties. The majority of the spectral energy of wind-induced vibrations was also concentrated at low frequencies $<100 \mathrm{~Hz}$ (Fig. 3), indicating that wind has the potential to mask the tremulatory signal of $C$. brevirostris.

The average peak wind velocity across all trail sites was $0.2 \mathrm{~m} / \mathrm{s}(\mathrm{SD} \pm 0.3 \mathrm{~m} / \mathrm{s})$, the maximum was $0.9 \mathrm{~m} / \mathrm{s}$, and the minimum was $0 \mathrm{~m} / \mathrm{s}$, or below the detection level of the wind meter. Wind gusts (velocity above $0 \mathrm{~m} / \mathrm{s}$ ) lasted from a few seconds to $10 \mathrm{~min}$. The windiest part of the night occurred from 22:00 at night to 2:00 in the morning, with an average wind velocity of $0.4 \mathrm{~m} / \mathrm{s}(S D \pm 0.3 \mathrm{~m} / \mathrm{s})$, peaking at $0.9 \mathrm{~m} / \mathrm{s}$. The most wind-free gaps were found from 2:00 to 6:00 in the morning, where the average wind velocity was $0.05 \mathrm{~m} / \mathrm{s}$ (SD $\pm 0.1 \mathrm{~m} / \mathrm{s}$ ) and the peak was $0.7 \mathrm{~m} / \mathrm{s}$ (Fig. 4). Tremulatory $(\mathrm{m} / \mathrm{s})$ are given in the bottom right of each graph. Vibrational noise of the silent treatment is included in all the panels for comparison

activity was significantly affected by time at night (Fig. 4, Friedman test, $d f=8, \chi^{2}=34.725, P<0.001$ ), with a higher number of tremulations produced between 2:00 and 5:00 in the morning. Male katydids produced an average of $96(\mathrm{SD} \pm$ 48) tremulations per hour between 2:00 and 5:00 in the morning, whereas they produced an average of $18(\mathrm{SD} \pm 18)$ tremulations per hour between 22:00 at night and 1:00 in the morning.

\section{Copiphora brevirostris tremulates more during wind-free gaps}

Males produced significantly fewer tremulations when exposed to wind gusts of $1.5 \mathrm{~m} / \mathrm{s}$ compared with the silent and the sound treatment (Fig. 5, Table 2). Additionally, males also produced significantly less tremulations during the lower intensity-wind treatment of $0.9 \mathrm{~m} / \mathrm{s}$ in comparison with the silent treatment, but not to the sound treatment (Fig. 5, Table 2). The inclusion of treatment and treatment level significantly improved the fit of the model $\left(\chi_{(1)}^{2}=40.582, P\right.$ $<0.001)$. Males produced an average of $3.1(\mathrm{SD} \pm 2.9)$ tremulations every $3 \mathrm{~min}$ during the lowest wind level, 2.1 $(\mathrm{SD} \pm 0.9)$ during $0.6 \mathrm{~m} / \mathrm{s}$, and $0.5(\mathrm{SD} \pm 1.1)$ tremulations when exposed to the highest wind level of $1.5 \mathrm{~m} / \mathrm{s}$. 
Fig. 2 Waveform (a) and power spectrum (b) of the tremulatory signal of a $C$. brevirostris male. Recording was made with a Laser Doppler Vibrometer from the side of a nylon cage (a)

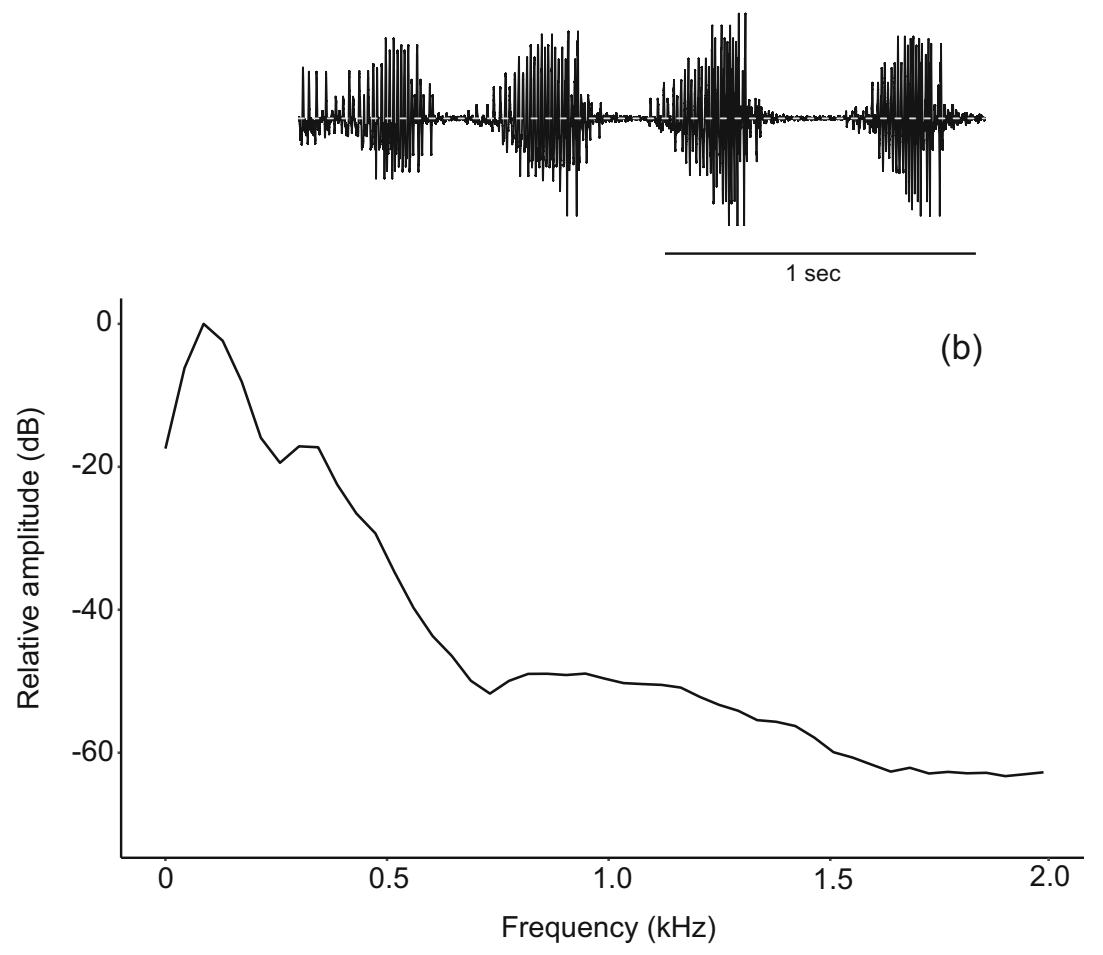

\section{Discussion}

In this study, we investigated whether wind affected the production of tremulatory signals in $C$. brevirostris and whether males of this species (1) signal at times at night when wind is typically low and (2) adjust their signaling activity in response to short-term fluctuations in wind. We found that wind levels were highest in the earlier part of the night between 22:00 and 2:00, whereas the most wind-free gaps occurred between 2:00 and 6:00 in the morning. In the lab, in the absence of wind,

Fig. 3 Amplitude spectra of (a) a tremulatory signal of male C. brevirostris and (b) windinduced vibrational noise $(0.9 \mathrm{~m} / \mathrm{s}$ for both) recorded from an Oenocarpus sp. palm and from the side of the cage in which the animals were tested

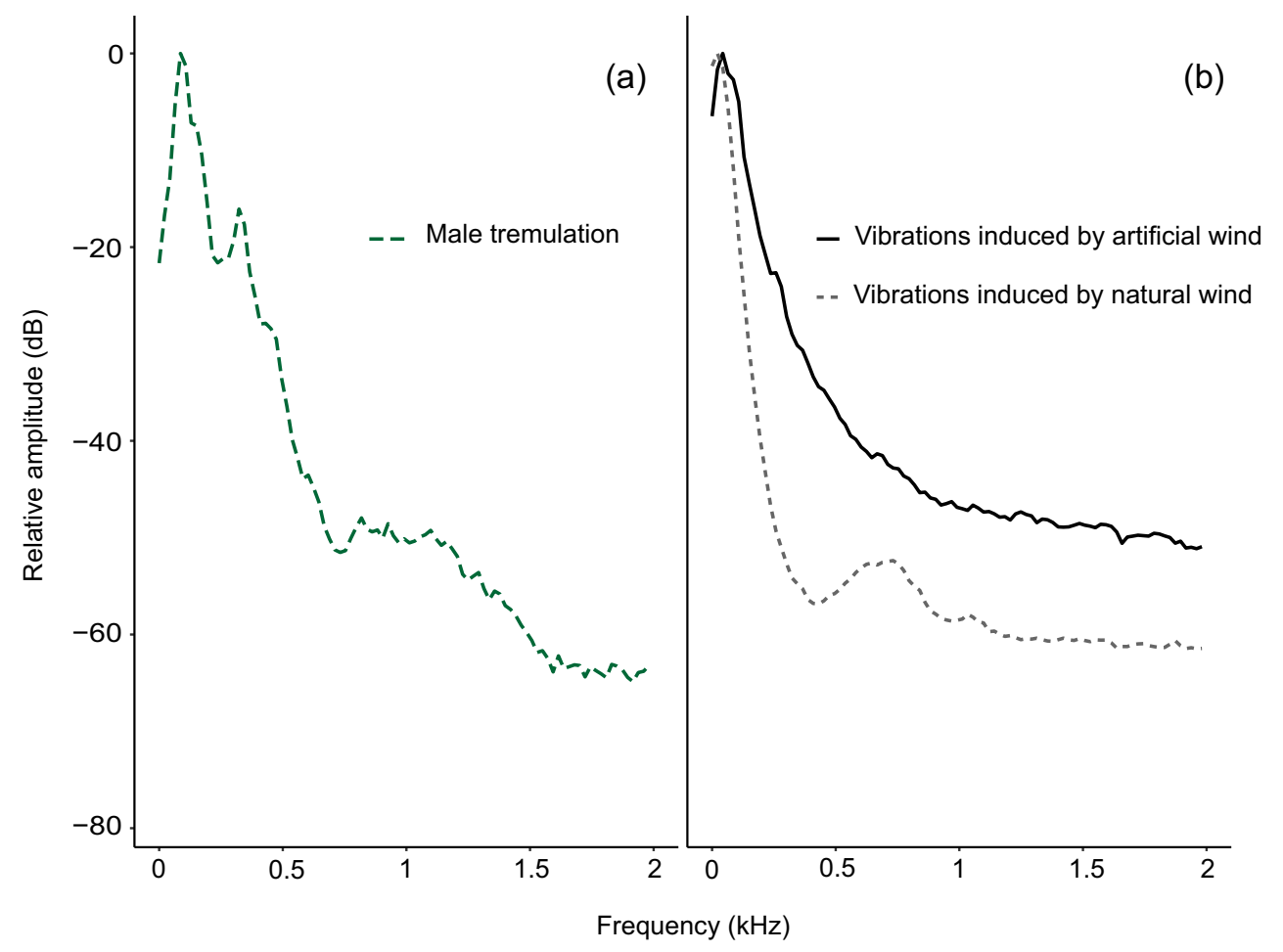


Fig. 4 a Mean peak wind velocity of all trails for the five nights of wind measurements. Peak wind velocity was recorded with a Kestrel 5500 wind meter, for every minute throughout the night, starting at 22:00 at night and ending at 07:00 in the morning. Blank spaces in the graph represent the times at night where wind velocity remained at $0 \mathrm{~m} / \mathrm{s}$ for all nights, for all trails. $\mathbf{b}$ Maximum peak wind of all trails for the five nights of wind measurements. Most wind-free gaps occur between 2:00 and 6:00 in the morning. c Male katydid signaling activity. Colored lines represent the signaling activity of individual male $C$. brevirostris $(n=$ 5). Male katydids, coupled with females, were video recorded overnight in a lab protected from wind and rain to quantify tremulations. Most tremulations are produced between 02:00 and 06:00 in the morning
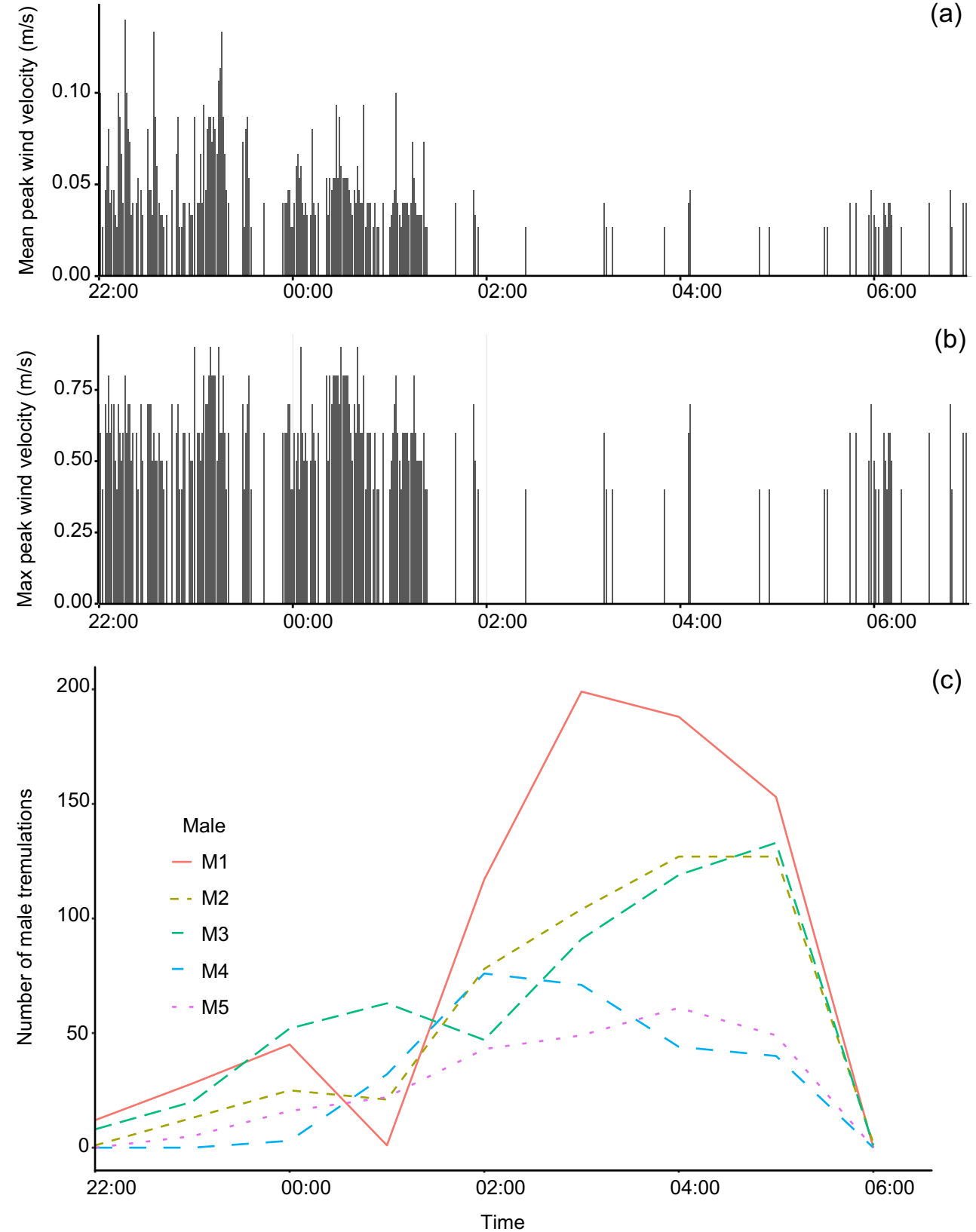

(c) katydid signaling activity was highest between 2:00 and 5:00 in the morning. Our results thus suggest that male katydids timed their signaling to the periods at night containing the most wind-free gaps under normal field conditions. Furthermore, when male katydids were exposed to wind gusts, even during their peak time of signaling activity, they tremulated significantly less than during the sound or silent treatments. This effect was mainly driven by the highest wind treatment level $1.5 \mathrm{~m} / \mathrm{s}$ and to a lesser extent by the $0.9 \mathrm{~m} / \mathrm{s}$ treatment level. Although we never recorded wind velocity levels of $1.5 \mathrm{~m} / \mathrm{s}$ in the field, $C$. brevirostris, as well as other katydid species, can be found higher in the vegetation and even in the canopy where wind levels are known to be higher than lower in the vegetation (Paton 2017, pers. obs.). For example, the average $\mathrm{BCI}$ wind velocity level measured in the canopy during the months of March and April 2017 was $2.3 \mathrm{~m} / \mathrm{s}(\mathrm{SD} \pm 0.9 \mathrm{~m} / \mathrm{s})$, with maximum levels of $7.7 \mathrm{~m} / \mathrm{s}$ (SD $\pm 1.5 \mathrm{~m} / \mathrm{s}$ ) (Paton 2017).

We did not find an effect of the sound-only treatment in which we controlled for the sounds produced by our fan. These results suggest that $C$. brevirostris would also not adjust its vibrational signaling behavior to the acoustic noise associated with natural wind, such as the sound of moving branches and leaves. However, wind not only induces sounds and vibrations but also fluctuations in airflow. Katydids, like other insects, have sensitive hairs that can detect airflow (Dupuy 
Fig. 5 Number of male tremulations produced by C. brevirostris during the different treatments per wind velocity block. The letters indicate significant pairwise differences $(P<0.05)$ calculated by means of a least square means test for multiple comparisons, with Bonferroni adjustment. The interquartile range was taken as the range from 0 to 25 th percentile. From the mean, the whiskers show the highest and lowest value within 1.5 times the interquartile range

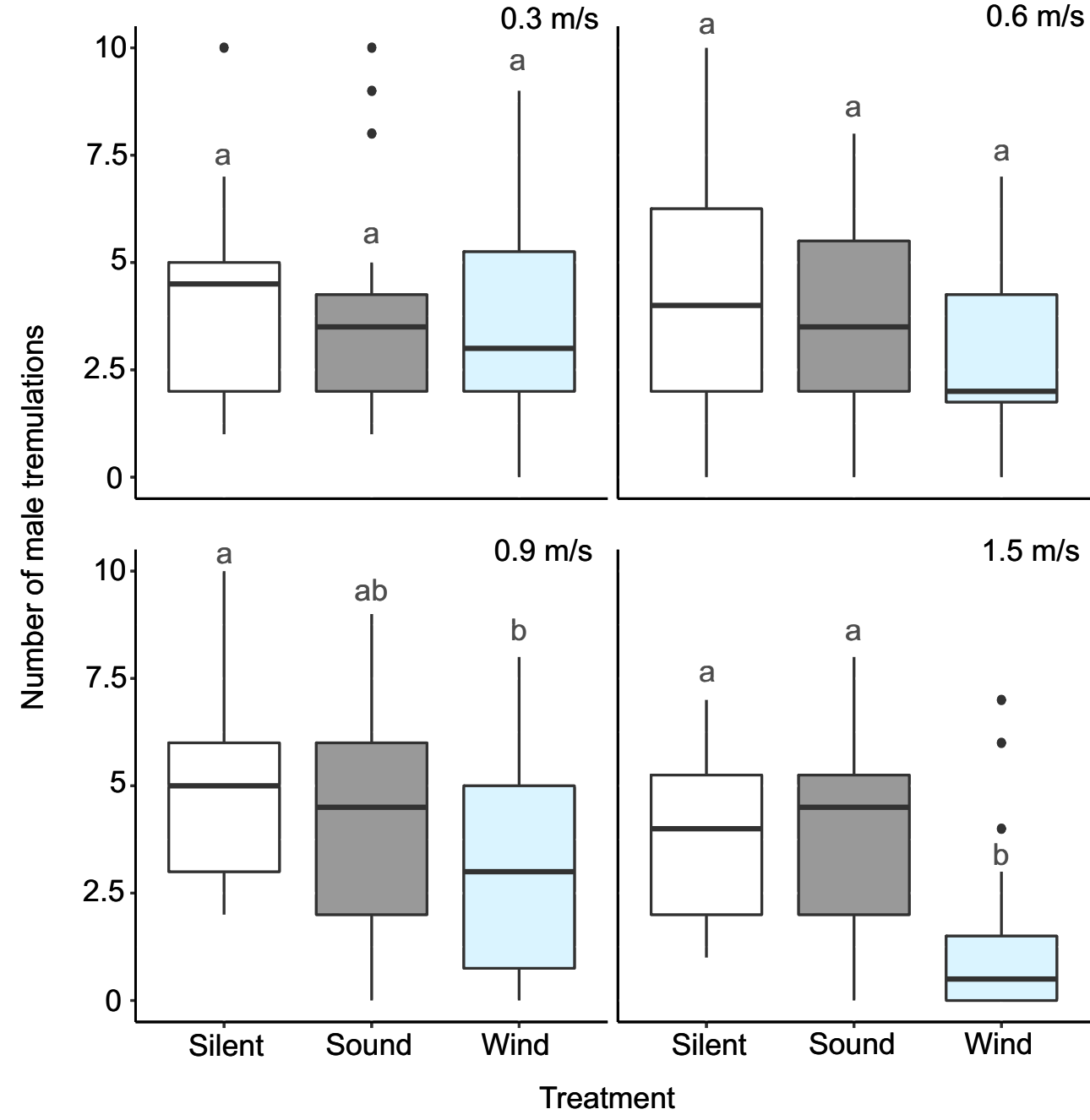

et al. 2011; Tuthill and Wilson 2016), which can be important for detecting attacking predators (Camhi et al. 1978;
Shimozawa et al. 2003). It is, therefore, possible that the airflow associated with wind hinders the ability of katydids to
Table 2 Estimates, standard error, $z$ ratio, and $P$ value from pairwise comparisons with $P$ value Bonferroni adjustment from a linear mixed effects model testing the effect of treatment and treatment level on the number of tremulations produced by males

\begin{tabular}{llllll}
\hline Treatment level & Contrast & Estimate & Std. error & z ratio & $P$ value \\
\hline $0.3 \mathrm{~m} / \mathrm{s}$ & Control-sound & 0.0307 & 0.175 & 0.176 & 1.0000 \\
& Control-wind & 0.1467 & 0.180 & 0.815 & 1.0000 \\
& Sound-wind & 0.1160 & 0.181 & 0.640 & 1.0000 \\
$0.6 \mathrm{~m} / \mathrm{s}$ & Control-sound & 0.1054 & 0.173 & 0.610 & 1.0000 \\
& Control-wind & 0.3983 & 0.188 & 2.122 & 0.1015 \\
& Sound-wind & 0.2929 & 0.192 & 1.527 & 0.3804 \\
$0.9 \mathrm{~m} / \mathrm{s}$ & Control-sound & 0.1431 & 0.169 & 0.848 & 1.0000 \\
& Control-wind & 0.4674 & 0.185 & 2.524 & $0.0348^{*}$ \\
& Sound-wind & 0.3243 & 0.191 & 1.701 & 0.2666 \\
$1.5 \mathrm{~m} / \mathrm{s}$ & Control-sound & -0.0481 & 0.178 & -0.270 & 1.0000 \\
& Control-wind & 0.9329 & 0.240 & 3.889 & $0.0003^{* *}$ \\
& Sound-wind & 0.9809 & 0.238 & 4.117 & $0.0001^{* *}$ \\
\hline
\end{tabular}

Per experimental trial, males were exposed to 9-min blocks of 3-min silence, 3-min wind, and 3-min fan sound per treatment level, randomizing the order of treatment and treatment level. The stars in the $P$ value column indicate statistical significance. Results are given on the log (not the response) scale 
detect approaching predators, increasing their perception of predation risk and leading to signaling inhibition. Based on our data, we cannot conclude whether the effect on signaling is due to katydids detecting the vibrations induced by wind or detecting the airflow itself. Future studies using shakers to reproduce the vibrational noise induced by wind are needed to further explore the effect of vibrational noise on signaling.

Animals using the acoustic or vibrational modality can adapt to communicating in noisy environments in different ways. For example, one strategy for senders to get their message across is to increase the amplitude of their signal, as has been recorded in birds (Slabbekoorn 2013), mammals (Sinnott et al. 1975), lizards (Brumm and Zollinger 2011), and frogs (Halfwerk et al. 2016a) or to avoid spectral and temporal overlap, e.g., robins (Fuller et al. 2007), great tits (Halfwerk and Slabbekoorn 2009), and bush crickets (Greenfield 1988). Our results indicate that $C$. brevirostris avoids temporal overlap, adjusting its signal timing by signaling more during less noisy times at night and by signaling more during the windfree gaps. Similar patterns of signal timing in response to wind have also been shown for Homoptera (Tishechkin 2007, 2013) and Membracidae insects (McNett et al. 2010), pointing toward a general trend for insects communicating with vibrational signals. Furthermore, because we only quantified the signaling activity and we did not record the signal during the experiments, we cannot tell from our data whether C. brevirostris males are also adapting their signal to avoid spectral overlap or to increase the amplitude of their signals.

Finally, senders can change the position from which they produce their signals to favor signal transmission (Nemeth et al. 2001), as shown in great tits (Halfwerk et al. 2012). We did not test plant-substrate preference for signaling. Therefore, we do not know whether $C$. brevirostris chooses plants that favor signal transmission, for instance, choosing plants that are stiffer and less responsive to wind. However, we collected katydids at night from different types of plants with different traits (e.g., large palm trees, heliconias, and small plants close to the ground). Assuming these katydids would be signaling from the plants on which we found them, and in light of the large trait variation in these plants, it is not likely that they choose a particular plant type that enhances signal transmission, especially as a way to deal with wind. It is possible, however, that $C$. brevirostris has a preference for locations highly shielded from the wind, as has been shown in small Homoptera, with animals concentrating mainly in places protected from the wind (Tishechkin 2013). It would be interesting to look into the relationship between wind intensity and number of katydids found in a particular substrate or in a particular location in the forest.

Signal timing, which can be important in behavioral interactions like mating or male-male interactions (Shaw and Galliart 1987; Greenfield and Roizen 1993; Dyson et al. 1994; Greenfield 1994; Grafe 1996; Brumm 2006; Höbel and Gerhardt 2007; Siegert et al. 2011; Symes et al. 2016), can be shaped by different selective pressures like characteristics of the transmission medium, noise, sexual selection, predation, and competition (Grafe 1996; Brumm 2006; Höbel 2010; McNett et al. 2010; Siegert et al. 2011). In the availability of females, predation pressure and weather conditions (wind and rain) have been suggested as factors shaping acoustic signal timing in nocturnal Orthoptera, where wind and rain increase predation risk and decrease signal transmission (Walker 1983). Copiphora brevirostris is a common prey of foliage-gleaning bats found in Gamboa and BCI (ter Hofstede et al. 2017), which are generally more active before midnight (Belwood 1990). The preference of $C$. brevirostris for signaling later at night, therefore, could also be explained by predator avoidance (Belwood and Morris 1987). However, Lophostoma silvicolum and Micronycteris microtis, some of the main bat predators of $C$. brevirostris, remain active throughout the entire night (Lang et al. 2005; Kalka and Kalko 2006), suggesting that predator avoidance is not the only factor affecting signal timing. Bat activity may not lead to a reduction or complete cessation of all signaling activity, but perhaps to cessation of acoustic calling activity only, at least in the forest understory. One explanation could be that C. brevirostris calls acoustically from higher in the vegetation, or even in the canopy before midnight to attract a female to a general focal area, and later descends into the understory to complete localization. Knowledge of the vertical distribution of this species in the forest and of its calling substrate preferences is needed to better understand the signaling strategies and mating interactions of $C$. brevirostris.

Acknowledgments We are thankful to Eleanor Gourevitch, Ciara E. Kernan, Sharon Martinson, Amber S. Litterer, and Luis Felipe Estrada for their help in the collection of C. brevirostris. Additionally, we are thankful to Jen Hamel for her advice on the recording of tremulations. This research was made possible in part by the Dr. J.L. Dobberke Foundation.

Funding information Estefania Velilla received additional funding in the form of a short-term fellowship from the Smithsonian Tropical Research Institute.

Data availability The datasets generated and analyzed during the current study are available from the corresponding author on reasonable request.

Open Access This article is licensed under a Creative Commons Attribution 4.0 International License, which permits use, sharing, adaptation, distribution and reproduction in any medium or format, as long as you give appropriate credit to the original author(s) and the source, provide a link to the Creative Commons licence, and indicate if changes were made. The images or other third party material in this article are included in the article's Creative Commons licence, unless indicated otherwise in a credit line to the material. If material is not included in the article's Creative Commons licence and your intended use is not permitted by statutory regulation or exceeds the permitted use, you will need to obtain permission directly from the copyright holder. To view a copy of this licence, visit http://creativecommons.org/licenses/by/4.0/. 


\section{References}

Bates D, Maechler M, Bolker B, Walker S, Christensen RHB, Singmann H, \& Bolker MB (2015). Package 'lme4'. Convergence 12(1):2

Barth FG, Bleckmann H, Bohnenberger J, Seyfarth EA (1988) Spiders of the genus Cupiennius Simon 1891 (Araneae, Ctenidae). Oecologia 77:194-201

Belwood JJ, Morris GK (1987) Bat predation and its influence on calling behavior in neotropical katydids. Science (80- ) 238:64-67

Belwood JJ (1990). The influence of bat predation on calling behavior in neotropical forest katydids (Insecta: Orthoptera: Tettigoniidae).

Bradbury JW, Vehrencamp SL (1998) Principals of animal communication, 2nd edn. Sinauer Associates, Sunderland

Brown TJ, Handford P (2003) Why birds sing at dawn: the role of consistent song transmission. Ibis (Lond 1859) 145:120-129. https:// doi.org/10.1046/j.1474-919X.2003.00130.x

Brumm H (2006) Signalling through acoustic windows: nightingales avoid interspecific competition by short-term adjustment of song timing. J Comp Physiol 192:1279-1285. https://doi.org/10.1007/ s00359-006-0158-x

Brumm H (2013) Animal communication and noise, 2nd edn. Springer Science \& Bursiness Media

Brumm H, Slabbekoorn H (2005) Acoustic communication in noise. Adv Study Behav 35:151-209. https://doi.org/10.1016/S0065-3454(05) 35004-2

Brumm H, Zollinger SA (2011) The evolution of the Lombard effect: 100 years of psychoacoustic research. Behaviour 148:1173-1198. https://doi.org/10.2307/41445240

Camhi JM, Tom W, Volman S (1978) The escape behavior of the cockroach Periplaneta americana. J Comp Physiol 128:203-212. https:// doi.org/10.1007/bf00656853

Casas J, Bacher S, Tautz J, Meyhöfer R, Pierre D (1998) Leaf vibrations and air movements in a leafminer-parasitoid system. Biol Control 11:147-153. https://doi.org/10.1006/bcon.1997.0593

Cocroft RB, Rodriguez RL (2005) The behavioral ecology of insect vibrational communication. Bioscience 55:323-334. https://doi.org/ 10.1641/0006-3568(2005)055[0323:TBEOIV]2.0.CO;2

Cocroft RB, Gogala M, Hill PS, Wessel A (eds) (2014) Studying vibrational communication, vol 3. Springer, Berlin

Dall SRX, Giraldeau LA, Olsson O et al (2005) Information and its use by animals in evolutionary ecology. Trends Ecol Evol 20:187-193. https://doi.org/10.1016/j.tree.2005.01.010

De Souza LR, Kasumovic MM, Judge KA, Morris GK (2011) Communicating male size by tremulatory vibration in a Columbian rainforest katydid, Gnathoclita sodalis (Orthoptera, Tettigoniidae). Behaviour 148:341-357. https://doi.org/10.1163/ $000579511 \times 559418$

Douglas HD, Conner WE (1999) Is there a sound reception window in coastal environments? Evidence from shorebird communication systems. Naturwissenschaften 86:228-230. https://doi.org/10.1007/ s001140050603

Dupuy F, Casas J, Body M, Lazzari CR (2011) Danger detection and escape behaviour in wood crickets. J Insect Physiol 57:865-871. https://doi.org/10.1016/j.jinsphys.2011.03.020

Dyson ML, Henzi SP, Passmore NI (1994) The effect of changes in the relative timing of signals during female phonotaxis in the reed frog, Hyperolius marmoratus. Anim Behav 48:679-685

Firebaugh A, Haynes KJ (2016) Experimental tests of light-pollution impacts on nocturnal insect courtship and dispersal. Oecologia 182:1203-1211. https://doi.org/10.1007/s00442-016-3723-1

Fox J, Weisberg S, Adler D, Bates D, Baud-Bovy G, Ellison S, \& Heilberger R. (2011). Package "car": Companion to applied regression.
Fuller RA, Warren PH, Gaston KJ (2007) Daytime noise predicts nocturnal singing in urban robins. Biol Lett 3:368-370. https://doi.org/10. 1098/rsbl.2007.0134

Grafe TU (1996) The function of call in the African tree frog (Hyperolius marmoratus): precise call timing prevents auditory masking. Behav Ecol Sociobiol 38:149-158

Greenfield MD (1988) Interspecific acoustic interactions among katydids Neoconocephalus: inhibition-induced shifts in diel periodicity. Anim Behav 36:684-695

Greenfield MD (1994) Cooperation and the conflict in the evolution of signal interactions. Annu Rev Ecol Syst 25:97-126

Greenfield MD, Roizen I (1993) Katydid synchronous chorusing is an evolutionarily stable outcome of female choice. Nature 364:618 620. https://doi.org/10.1038/364618a0

Halfwerk W, Slabbekoorn H (2009) A behavioural mechanism explaining noise-dependent frequency use in urban birdsong. Anim Behav 78:1301-1307

Halfwerk W, Bot S, Slabbekoorn H (2012) Male great tit song perch selection in response to noise-dependent female feedback. Funct Ecol 26:1339-1347. https://doi.org/10.1111/j.1365-2435.2012. 02018.x

Halfwerk W, Lea AM, Guerra MA, Page RA, Ryan MJ (2016a) Vocal responses to noise reveal the presence of the Lombard effect in a frog. Behav Ecol 27:669-676. https://doi.org/10.1093/beheco/ arv204

Halfwerk W, Ryan MJ, Wilson PS (2016b) Wind- and rain-induced vibrations impose different selection pressures on multimodal signaling. Am Nat 188:279-288. https://doi.org/10.1086/687519

Höbel G (2010) Interaction between signal timing and signal feature preferences: causes and implications for sexual selection. Anim Behav 79:1257-1266. https://doi.org/10.1016/j.anbehav.2010.02. 026

Höbel G, Gerhardt HC (2007) Sources of selection on signal timing in a tree frog. Ethology 113:973-982. https://doi.org/10.1111/j.14390310.2007.01404.x

Hopkins CD (1973) Lightning as background noise for communication among electric fish. Nature 242:268-270. https://doi.org/10.1038/ $242268 \mathrm{a} 0$

Schwartz JJ, Wells KD, (1983) An experimental study of acoustic interference between two species of neotropical treefrogs. Animal Behaviour 31 (1):181-190

Kalka M, Kalko EKV (2006) Gleaning bats as underestimated predators of herbivorous insects: diet of Micronycteris microtis (Phyllostomidae) in Panama. J Trop Ecol 22:1-10. https://doi.org/ $10.1017 / \mathrm{S} 0266467405002920$

Lang A, Teppner I, Hartbauer M, Romer H (2005) Predation and noise in communication networks of neotropical katydids. In: Peter K. McGregor (ed). Cambridge University Press

Lenth R, \& Lenth MR (2018). Package 'lsmeans'. The American Statistician, 34(4):216-221.

McNett GD, Luan LH, Cocroft RB (2010) Wind-induced noise alters signaler and receiver behavior in vibrational communication. Behav Ecol Sociobiol 64:2043-2051. https://doi.org/10.1007/ s00265-010-1018-9

Morris GK, Mason AC, Wall P (1994) High ultrasonic and tremulation signals in neotropical katydids (Orthoptera: Tettigoniidae). J Zool 233:129-163. https://doi.org/10.1111/j.1469-7998.1994.tb05266.x

Morris GK (1980) Calling display and mating behaviour of Copiphora rhinoceros Pictet (Orthoptera: Tettigoniidae). Animal Behaviour 28 (1):42-IN1

Naguib M (2013) Living in a noisy world: indirect effects of noise on animal communication. Behaviour 150:1069-1084. https://doi.org/ 10.1163/1568539X-00003058

Nemeth E, Winkler H, Dabelsteen T (2001) Differential degradation of antbird songs in a neotropical rainforest: adaptation to perch height? 
J Acoust Soc Am 110:3263-3274. https://doi.org/10.1121/1. 1420385

Paton S (2017). Metereological and Hydrological Summary for Barro Colorado Island. Smithsonian Tropical Research Institute.

R Core Team (2016) R: A Language and Environment for Statistical Computing. R Foundation for Statistical Computing, Vienna, Austria. https://www.R-project.org/

Römer H, Lang A, Hartbauer M (2010) The signaller's dilemma: a costbenefit analysis of public and private communication. PLoS One 5: e13325. https://doi.org/10.1371/journal.pone.0013325

RStudio Team (2015) RStudio: Integrated Development for R. RStudio Inc, Boston MA (Computer Software v0.98.1074). http:// www.rstudio.com/

Sarria-S FA, Buxton K, Jonsson T, Montealegre-Z F (2016) Wing mechanics, vibrational and acoustic communication in a new bushcricket species of the genus Copiphora (Orthoptera: Tettigoniidae) from Colombia. Zool Anz 263:55-65. https://doi.org/10.1016/j.jcz. 2016.04.008

Shaw KC, Galliart P (1987) Acoustic and mating behavior of a Mexican katydid, Pterophylla beltrani (Orthoptera: Tettigoniidae). Florida Entomol 70:354-368

Shimozawa T, Murakami J, \& Kumagai T (2003). Cricket wind receptors: thermal noise for the highest sensitivity known. In Sensors and sensing in biology and engineering. Springer, Vienna 145-157

Siegert ME, Römer H, Hashim R, Hartbauer M (2011) Neuronal correlates of a preference for leading signals in the synchronizing bushcricket Mecopoda elongata (Orthoptera, Tettigoniidae). J Exp Biol 214:3924-3934. https://doi.org/10.1242/jeb.057901

Sinnott JM, Stebbins WC, \& Moody DB (1975). Regulation of voice amplitude by the monkey. The Journal of the Acoustical Society of America, 58(2), 412-414.

Slabbekoorn H (2013) Songs of the city: noise-dependent spectral plasticity in the acoustic phenotype of urban birds. Anim Behav 85: 1089-1099. https://doi.org/10.1016/j.anbehav.2013.01.021

Symes LB, Page RA, Hofstede HM (2016) Effects of acoustic environment on male calling activity and timing in neotropical forest katydids. Behav Ecol Sociobiol 70:1485-1495. https://doi.org/10. 1007/s00265-016-2157-4

ter Hofstede H, Voigt-Heucke S, Lang A, Römer H, Page R, Faure P, Dechmann D (2017) Revisiting adaptations of neotropical katydids (Orthoptera: Tettigoniidae) to gleaning bat predation. Neotrop Biodivers 3:41-49. https://doi.org/10.1080/23766808.2016. 1272314

Tishechkin DY (2007) Background noises in vibratory communication channels of Homoptera (Cicadinea and Psyllinea). J Russ Entomol 16:39-46

Tishechkin DY (2013) Vibrational background noise in herbaceous plants and its impact on acoustic communication of small Auchenorrhyncha and Psyllinea (Homoptera). Entomol Rev 93:548-558. https://doi.org/ $10.1134 / \mathrm{S} 0013873813050035$

Tuthill JC, Wilson RI (2016) Mechanosensation and adaptive motor control in insects. Curr Biol 26:R1022-R1038. https://doi.org/10.1016/ j.cub.2016.06.070

Velilla E, Halfwerk W (2019) Adjustments to facilitate communication in noisy environments. In: Choe JC (ed) Encyclopedia of Animal Behavior, 2nd ed. Elsevier, pp 598-605

Virant-Doberlet M, Mazzoni V, de Groot M, Polajnar J, Lucchi A, Symondson WOC \& Cokl Andrej (2014). in Cocroft RB, Gogala M, Hill PSM, Wessel A (eds). Studying Vibrational Communication. Berlin:Springer (3)

Walker TJ (1983) Diel patterns of calling in nocturnal Orthoptera. Orthopteran Mating Syst Sex Compet a Divers Gr Insects:44-72

Ward AJW, Duff AJ, Horsfall JS, Currie S (2008) Scents and scentsability: pollution disrupts chemical social recognition and shoaling in fish. Proc R Soc B Biol Sci 275:101-105. https://doi.org/10.1098/ rspb.2007.1283

Publisher's note Springer Nature remains neutral with regard to jurisdictional claims in published maps and institutional affiliations. 